\title{
d-q Control Scheme for Unified Power Flow Controller
}

\author{
D.O.I - 10.51201/12520 \\ https://doi.org/10.51201/12520
}

\author{
Rohan S. Khonde ${ }^{* 1}$, Priya P. Gaikwad ${ }^{2}$, Sandeep R. Gaigowal ${ }^{3}$, Manisha Gaikwad ${ }^{4}$ \\ ${ }^{1,3}$ Yeshwantrao Chavan College of Engineering, Nagpur (M.S.), India \\ ${ }^{2}$ Priyadarshini College of Engineering, Nagpur (M.S.), India \\ ${ }^{4}$ Shri Ramdeobaba College of Engineering \& Management, Nagpur (M. S.), India
}

\begin{abstract}
Unified Power Flow Controller (UPFC) is the most prominent versatile FACTS controller applied in power system providing dynamic control of transmission line parameters. It can achieve Voltage regulation, series compensation and phase shifting independently. It provides combined advantages of STATCOM and SSSC by connecting two VSC's with common dc coupling. Active power and reactive power can be directly controlled using UPFC. This paper presents UPFC for active power flow control through transmission lines. Control scheme based on d-q transformation is demonstrated. System studies are presented in MATLAB Simulink to present the active power flow control in the line.
\end{abstract}

Keywords: FACTS, Unified power flow controller (UPFC), instantaneous p-q theory.

\section{Introduction}

In the last three-four decades, Indian economy has grown faster amongst the developing countries. Per capita electricity consumption is increasing day to day. Major power generation is through coal based power plants. Renewable energy is also supplemented along with generation using Fossil Fuel. Near about $36 \%$ of the installed capacity is power generation through renewable energy. Even with this surplus power, India lacks an adequate transmission network. New transmission network erection seems to be difficult due to long building cycles, many environmental permission issues, and land acquisition problems. Hence, existing lines are carrying more power above its thermal limits; it may happen that some lines are still under loaded. Hence power agencies are focusing on utilization of existing transmission networks to its fullest extent. The uncontrolled power flow can be controlled with Flexible AC Transmission system (FACTS) [1]. First generation FACTS controllers like Static VAR Compensator (SVC) and Thyristor Controlled Series Capacitor (TCSC) are conventional FACTS devices which comprise inductor and capacitor with power electronics device control. With the advent of new high power rating and fast acting power electronics switches, FACTS technology becomes more popular and achieves a wide control area. Static Compensator (STATCOM), Static Synchronous Series Compensator (SSSC) and UPFC are modern VSC based FACTS controllers which use high power rating converters. STATCOM comprises VSC connected in shunt at PCC with the help of coupling transformer. It exchanges reactive power at the PCC to maintain bus voltage and controlling reactive power, indirectly controls active power flow in the line [2]. SSSC is a series connected FACTS controller. It is connected in series with the line with the help of a coupling transformer. It injects voltage in the line in quadrature with line current and achieves reactance compensation to control active power flow in the line. UPFC consists of shunt as well as series converter as if like STATCOM and SSSC. Both converters are coupled with a common dc link. UPFC can control bus voltage, line reactance and power angle 
independently [3], [4]. Many literatures are available on FACTS controllers [5]-[7]. D. Diwan proposed distributed FACTS concept. Distributed series FACTS controllers' controls power flow in the line in cost effective way and reliable manner. [8]-[10].

This paper presents UPFC to realize active power flow control through transmission line. MATLAB simulations are presented to validate the power flow control through the transmission line. Control scheme based on p-q theory is implemented to generate shunt and series VSC. Paper starting with the introduction, next sections cover UPFC structure and control scheme. System studies on MATLAB Simulink are put in last section and at last conclusion is written.

\section{Unified Power Flow Controller}

The concept of Unified Power Flow Controller was proposed by Gyugyi in 1991. The UPFC was developed for real time control \& with dynamic compensation of ac transmission network. The factors affecting power flow of transmission line (i.e. voltage, impedance and phase angle) can be control simultaneously or selectively with the help of the UPFC. The basic structure of the UPFC consist of two voltage source converters connected back to back with common dc link delivered by the dc loading capacitor. The ideal function of these back to back converters is to transfer real power freely in both the direction between the terminals of two converters. Both converters can independently supply or absorb reactive power at its terminal of ac output.

Out of the back to back converters one is connected in series with transmission line act as a series converter \& other is connected in shunt with the line as a shunt converter with help of series transformer and supply transformer respectively. The main function of series converter is to injecting voltage with controllable magnitude and phase angle in series with the line via series connected transformer. The real power needed by series converter is to be supplied from shunt converter through the common dc link is the basic function of shunt converter.

\section{UPFC control scheme based on p-q theory}

UPFC is a versatile FACTS controller since it provides active and reactive power flow control, reactance compensation, and voltage regulation, reactive power support at bus and phase angle regulator tasks with the help of shunt and series converter. Basically, series VSC controller provides power flow control in the line and shunt VSC controller performs voltage regulation at the bus. Concept of $\mathrm{p}-\mathrm{q}$ theory applied to UPFC is to maintain the bus voltage and power flow control in the line [11]. Two control schemes are applied; shunt and series VSC control. Function of series VSC control is to control injected compensating voltage $V_{\text {se }}$ to get desired active and reactive power flow control. Function of shunt VSC control is to control reactive component of compensating current $I_{s h}$ to maintain dc link voltage reference to desired bus and de link voltage is also maintained. 


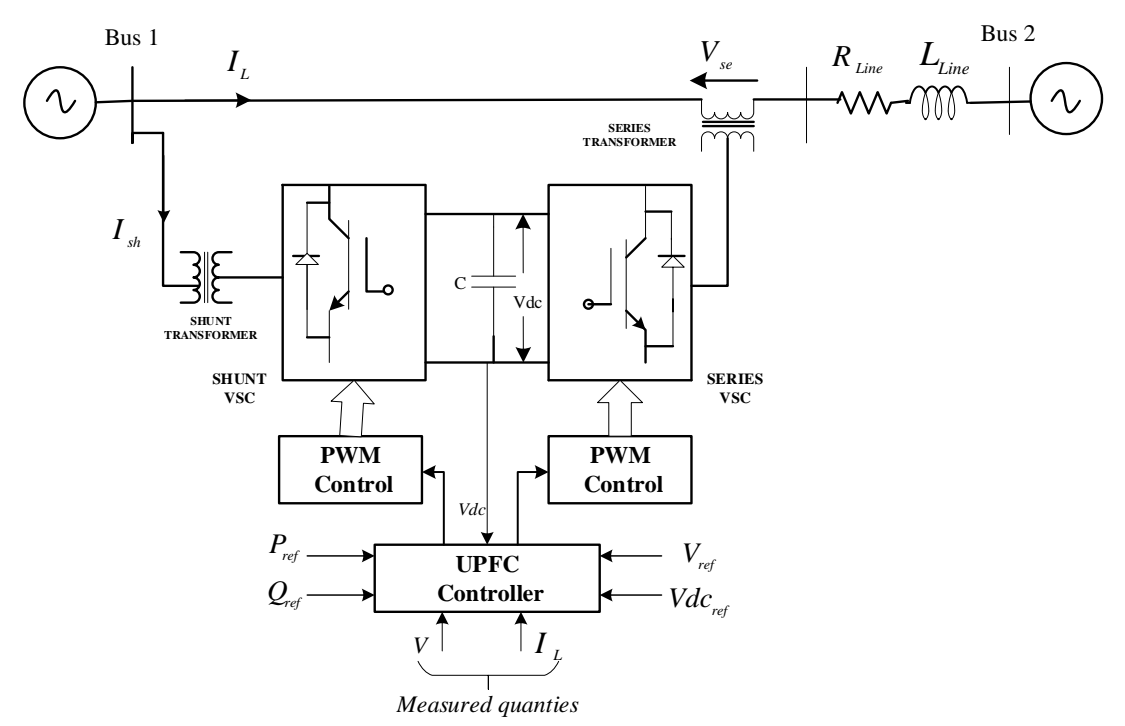

Fig. 2 Basic control scheme of UPFC [11]

Fig. 2 shows basic control scheme of UPFC. Bus voltage $V$, line current $I_{L}$, injected voltage $V_{s e}$ and shunt current $I_{s h}$ are measured quantities. UPFC controller output variables are $V^{*}{ }_{s e}$ and $I{ }_{s h}$. PWM pulses for shunt converter are generated with respect to reference generated $I^{*}{ }_{s h}$ and PWM pulses for series converter are generated with respect to generated $V^{*}$ se.

Fig. 3 presents series VSC control of UPFC, where reference power is compared with actual measured power and correspondingly reference for PWM pulses is generated.

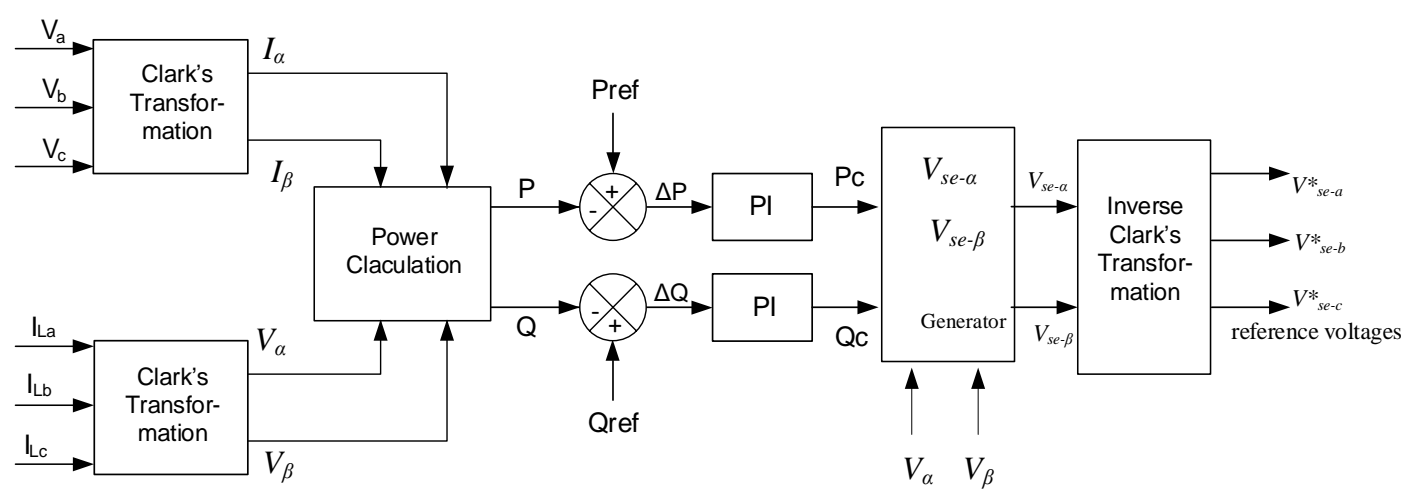

Fig. 3 Series VSC control scheme of UPFC

Applying Clarke's transformation, bus 1 voltage $V_{a}, V_{b}, V_{c}$ is transformed to $V_{a}, V_{\beta}, V_{0}$ and line current $I_{a}, I_{b}, I_{c}$ is transformed to $I_{\alpha}, I_{\beta}, I_{0}$. Active and reactive power is calculated. $P$ and $Q$.

In shunt converter control, These $P$ and $Q$ is compared with reference i.e. desired active and reactive power.

System voltage $V_{\alpha}, V_{\beta}$, neglecting zero sequence components, given in equation (1),

$$
\left[\begin{array}{l}
V_{\alpha} \\
V_{\beta}
\end{array}\right]=\sqrt{\frac{2}{3}}\left[\begin{array}{ccc}
1 & -\frac{1}{2} & -\frac{1}{2} \\
0 & \frac{\sqrt{3}}{2} & -\frac{\sqrt{3}}{2}
\end{array}\right]\left[\begin{array}{l}
V_{a} \\
V_{b} \\
V_{c}
\end{array}\right]
$$


Line current, $I_{a}, I_{b}, I_{c}$ is transformed to $I_{\alpha,} I_{\beta}, I_{o}$. Neglecting zero sequence components and applying $I_{c}=-I_{a}-I_{b}$

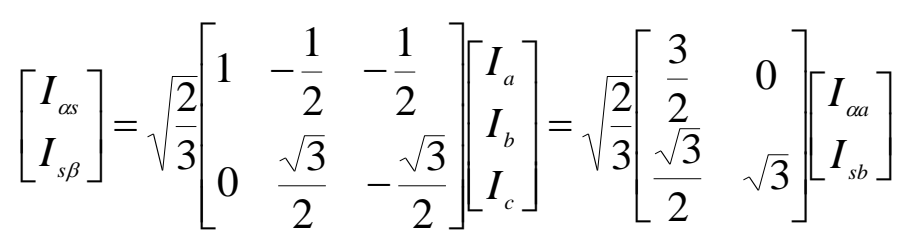

From equation (3), Active and reactive power in the line is,

$$
\left[\begin{array}{l}
P \\
Q
\end{array}\right]=\left[\begin{array}{cc}
V_{\alpha} & V_{\beta} \\
V_{\beta} & -V_{\alpha}
\end{array}\right]\left[\begin{array}{l}
I_{s \alpha} \\
I_{s \beta}
\end{array}\right]
$$

In series converter control of UPFC, instantaneous power $P, Q$ is compared with reference $P_{r e f}$ and $Q_{r e f}$ respectively. Difference $\Delta P$ and $\Delta Q$ is passed through two PI controllers respectively, producing correction factor $P_{c}$ and $Q_{c}$. Applying instantaneous power theory, $V_{s e-\alpha}$ and $V_{s e-\beta}$ is generated, which will be further pass on to inverse Clarke's transformation and final $V_{s e-a}, V_{s e-b}$ and $V_{s e-c}$ reference voltages are generated for PWM of series converter.

Applying to find $V^{*}{ }_{s e-a}, V^{*}{ }_{s e-b}$ and $V^{* e-c}$ reference voltages

$$
\begin{aligned}
& {\left[\begin{array}{c}
V_{s e-\alpha}^{*} \\
V_{s e-\beta}^{*}
\end{array}\right]=\frac{1}{V_{\alpha}^{2}+V_{\beta}^{2}}\left[\begin{array}{cc}
V_{\alpha} & V_{\beta} \\
V_{\beta} & -V_{\alpha}
\end{array}\right]\left[\begin{array}{c}
P c \\
Q c
\end{array}\right]}
\end{aligned}
$$

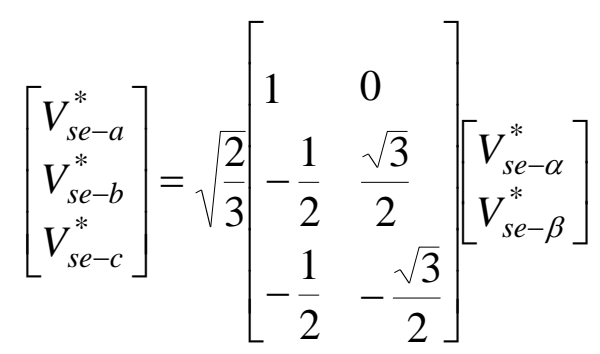

Shunt converter of UPFC also provide energy balance in dc link. Shunt converter provide an equal amount of average active power that is equal to the amount of active power injected by series converter of UPFC. Fig. 4 shows shunt VSC control of UPFC. In shunt converter control of UPFC, instantaneous aggregate value is compared with reference bus voltage $V d c_{r e f}$ and difference $\Delta V$ is nullified by applying PI controller. A correction factor $P_{l}$ is generated which will realize to maintain bus voltage in the system. A dc link voltage is maintained constant by applying closed loop control. Actual dc link voltage $V_{d c}$ is compared with reference value of dc link voltage $V_{d c r e f}$. A difference in voltage is nullified by implementing PI controller and gives output as $Q_{2}$. Applying instantaneous power theory, $I^{*}{ }_{s h-\alpha}$ and $I^{*}{ }_{s h-\beta}$ are generated. Inverse Clarke's transformation is applied which gives reference of shunt converter PWM. 


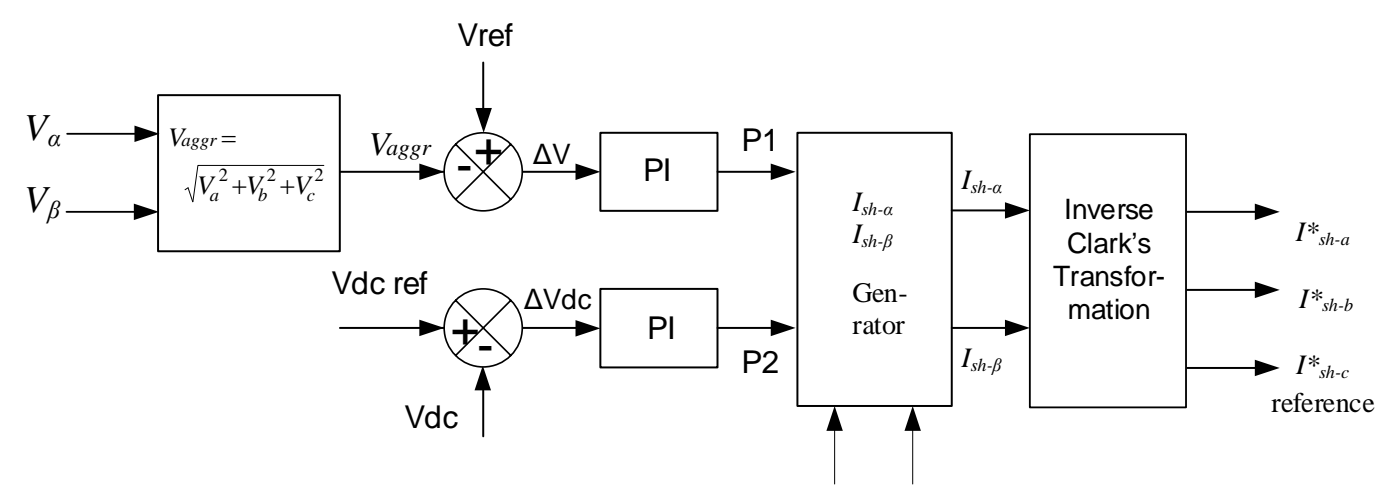

Fig. 4 Shunt VSC control scheme of UPFC

$$
\left[\begin{array}{c}
I_{s h-\alpha}^{*} \\
I_{s h-\beta}^{*}
\end{array}\right]=\frac{1}{V_{\alpha}^{2}+V_{\beta}^{2}}\left[\begin{array}{cc}
V_{\alpha} & V_{\beta} \\
V_{\beta} & -V_{\alpha}
\end{array}\right]\left[\begin{array}{l}
P_{1} \\
Q_{2}
\end{array}\right]
$$

Reference for PWM control of shunt converter is given by,

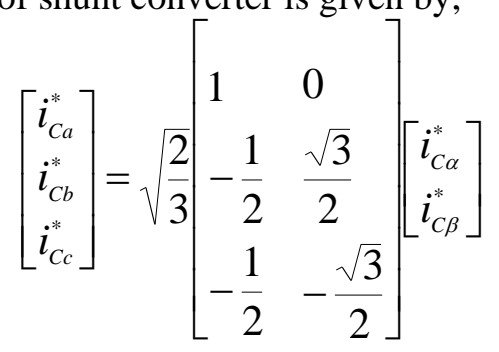

By implementing references for PWM of shunt and series, converter pulses are generated. When series converter is operated with these pulses, voltage $V_{s e}$ is injected in series with the line and gives desired power flow in the line. Similarly, shunt converter is operated with PWM pulses generated with reference $I^{*}{ }_{s h-a}, I^{*}{ }_{s h-b}$ and $I^{*}{ }_{s h-c}$ and desired voltage is obtained at the bus.

\section{Simulation Results}

A two bus system shown in Fig. 5 is considered to simulate UPFC controller. Shunt and series converter is connected through common dc link. Active power flow in the transmission line is controlled by UPFC. Series VSC injects voltage in series with the line. Active power will be taken from the line itself to maintain dc link voltage. 


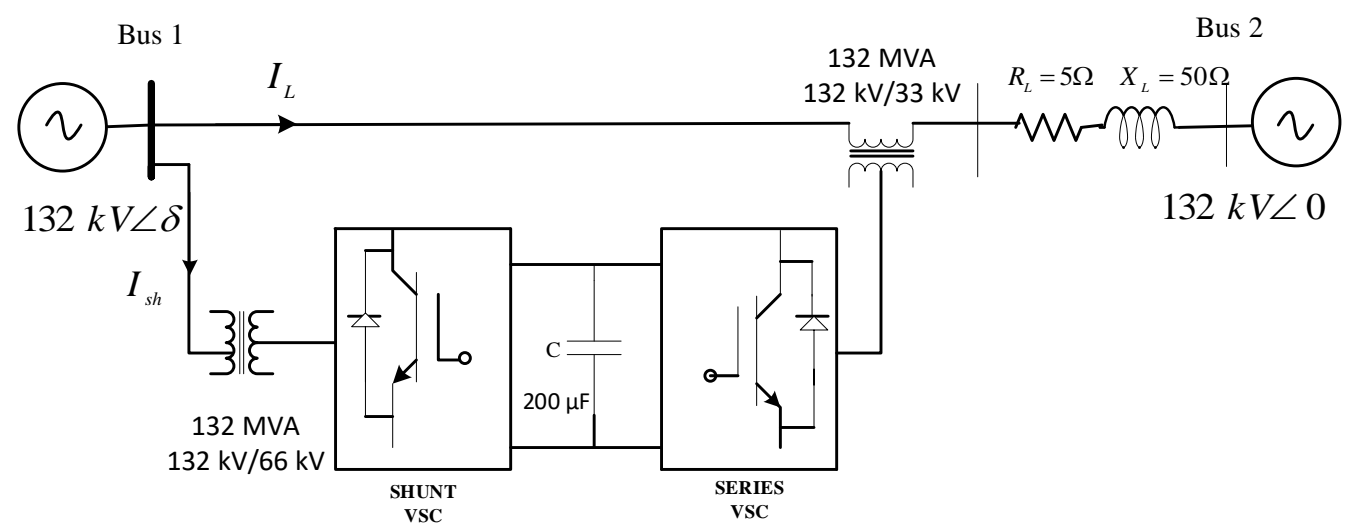

Fig. 5 UPFC compensated system for simulation

Active and reactive power flow when UPFC is not connected is determined. The sending end voltages are operated with $132 \mathrm{kV}$ at an angle of $30^{\circ}$. The real and reactive power transmitted is as shown in Fig 6.
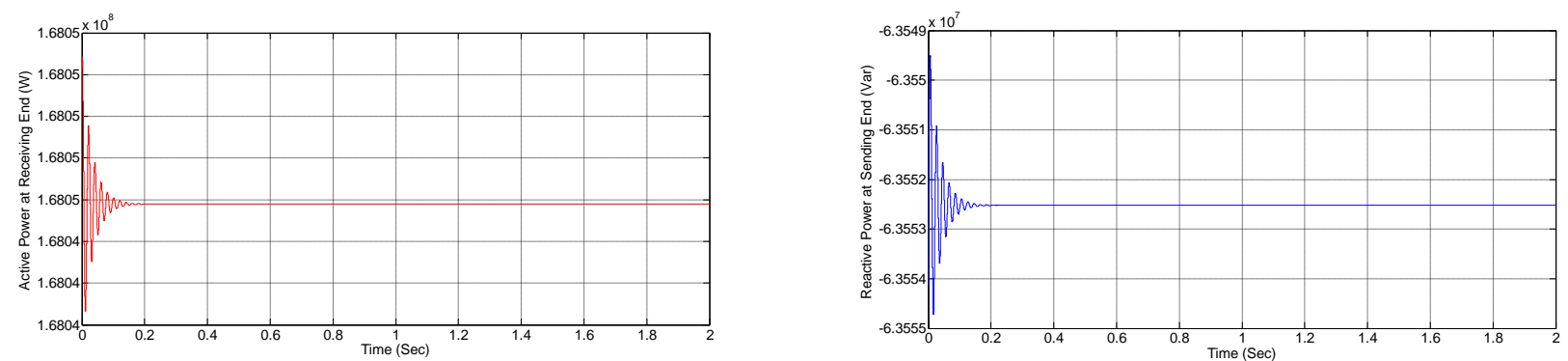

Fig. 6 Active and Reactive power at Bus 2 uncompensated system (receiving end)
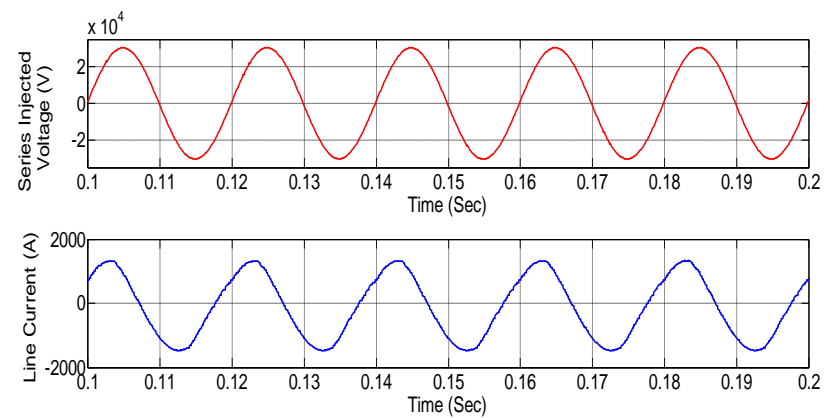

Fig. 7 Series injected voltage and line current Phase A

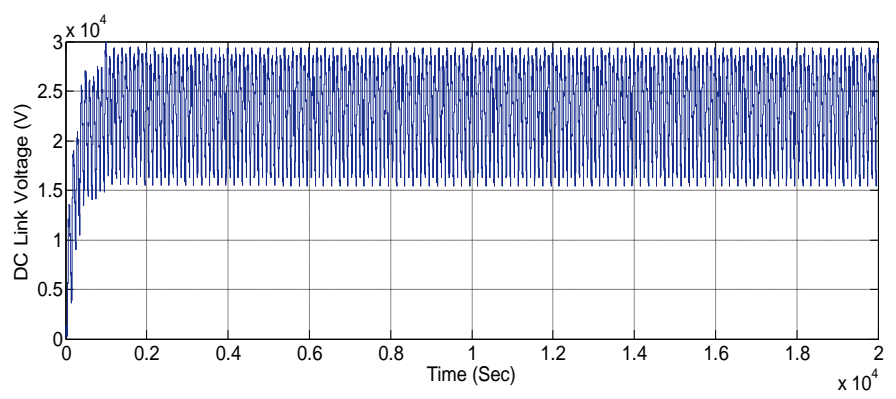

Fig. 8 DC link capacitor voltage 

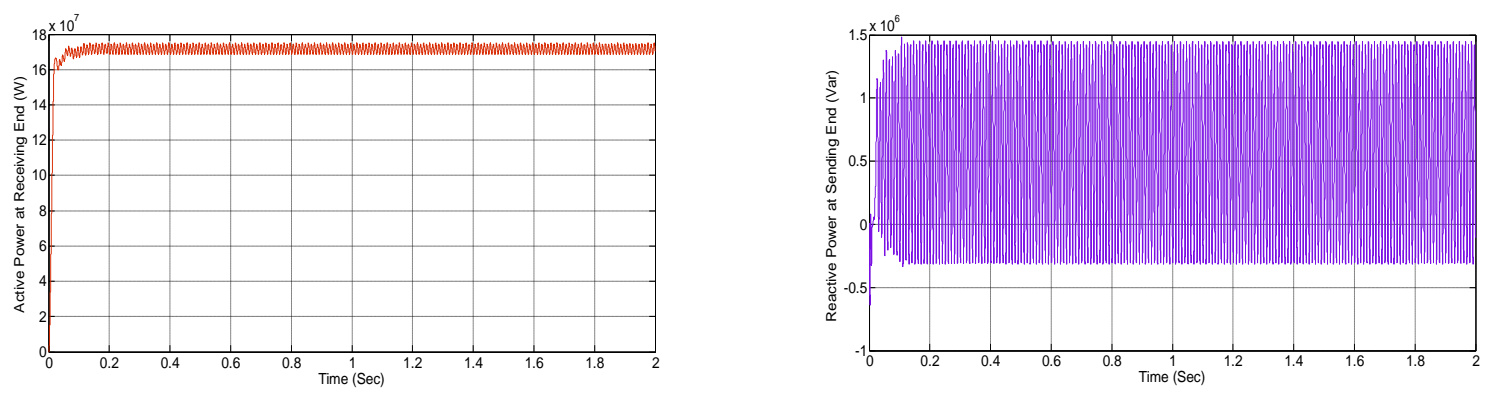

Fig. 9 Active and Reactive Power of bus 2 (compensated system)

UPFC is connected in the system shown in Fig. 5. The instantaneous power theory is applied here for controlling purpose. Shunt and series VSC gate pulse generation is generated with respect to desired power given as reference. Series VSC injects voltage in series with the line. Injected voltage and line current waveform is shown in Fig. 7.

Active and reactive power at bus 2 (receiving end) is shown in Fig. 8. Active power is found increased. The simulation results show there is an improvement in power transfer when UPFC is connected with the system as compared to without UPFC.

Table 1: Un-Compensated and compensated active and reactive power flow in the line

\begin{tabular}{|c|c|c|c|c|}
\hline & \multicolumn{2}{|c|}{ Sending end } & \multicolumn{2}{c|}{ Receiving end } \\
\hline Power & $P_{1}$ & $Q_{1}$ & $P_{2}$ & $Q_{2}$ \\
\hline Uncompensated System & $177 \mathrm{MW}$ & $28 \mathrm{MVAr}$ & $167 \mathrm{MW}$ & $-63.55 \mathrm{MVAr}$ \\
\hline $\begin{array}{c}\text { UPFC Compensated } \\
\text { system }\end{array}$ & $178 \mathrm{MW}$ & $-43.05 \mathrm{MVAr}$ & $176 \mathrm{MW}$ & $-0.105 \mathrm{MVAr}$ \\
\hline
\end{tabular}

\section{Conclusion}

UPFC is a combined shunt and series compensation device which alters transmission parameters to control power flow in the line. This paper presents active power flow control in the line with UPFC. A control scheme based on p-q theory is implemented to generate reference signals for PWM of shunt and series VSC of UPFC. MATLAB simulation studies are carried out on two bus system. Active power flow in the line is found increased with UPFC compensation.

\section{REFERENCES}

1. N. G. Hingorani and L. Gyugyi, "Understanding FACTS: Concepts and Technology of Flexible AC Transmission Systems”. IEEE Press (2000).

2. R. M. Mathur and R.K. Varma, "Thyristor-Based FACTS Controller for Electrical Transmission System”. IEEE Press and Wiley Interscience, New York (2002).

3. K. R. Padiyar, "FACTS Controllers in power Transmission and Distribution", New Age International, New Delhi, (2007).

4. K. K. Sen, "SSSC: Theory, modelling and applications", IEEE Transactions on power delivery, Vol. 13, No. 1, Jan. (1998).

5. C. D. Schauder and E.M.Hamai, "Operation of unified power flow controller (UPFC) under practical constraints”. IEEE Trans. Power Del., vol. 13, no. 2, (1998), pp.630 -639.

6. A. Shiwalkar and N. D. Ghawghawe, "Power flow control through transmission line with UPFC to mitigate contingency”. International Journal of Advanced Electrical and Electronics Engineering, Volume-1, Issue-2 (2012). 
7. Z. Huang, "Application of UPFC in interconnected power systems, modelling, interface, control strategy, and case study”. IEEE Trans. Power Syst., vol. 15, no. 2, (2000), pp.817 -824.

8. D. Divan, W. Brumsickle, R. Schneider, B. Kranz, R. Gascoigne, D. Bradshaw, M. Ingram, I. Grant. 2007. A distributed static series compensator system for realizing active power flow control on existing power lines. IEEE Trans. Power Del., vol. 22, no. 1, (2007), pp. 642-649.

9. Sandeep R. Gaigowal, M. M. Renge, "Some studies of Distributed Series FACTS Controller to control active power flow through Transmission Line”. IEEE International Conference on Power, Energy and Control (ICPEC), (2013), pp 124-128.

10. Sandeep R. Gaigowal, M. M. Renge, "Distributed power flow controller using single phase DSSC to realize active power flow control through transmission line". International Conference on Computation of Power, Energy Information and Communication (ICCPEIC), (2016).

11. Hirofumi Akagi, Edson H. Watanabe, M. Arede, "Instantaneous power Theory and Applications to power Conditioning”. IEEE press (2007). 